\title{
Trauma Surgery
} \& Acute Care Open

\section{David V Feliciano}

Department of Surgery, University of Maryland School of Medicine, Baltimore, Maryland, USA

\section{Correspondence to}

Dr David V Feliciano,

Department of Surgery, University of Maryland School of Medicine, Baltimore, MD 21201 1595, USA; davidfelicianomd@ gmail.com

Received 19 October 2018 Accepted 22 October 2018 (c) Author(s) (or their employer(s)) 2018. Re-use permitted under CC BY-NC. No commercial re-use. See rights and permissions. Published by BMJ.

To cite: Feliciano DV. Trauma Surg Acute Care Open 2018;3:e000273.

\section{HISTORY}

A 25-year-old man presented to the trauma center with a close-range shotgun wound to the left proximal thigh.

\section{EXAMINATION}

The patient was awake and alert with a heart rate of 120 beats per minute and a systolic blood pressure of $90 \mathrm{~mm} \mathrm{Hg}$. A pressure dressing on the left proximal thigh which was applied in the field was half-saturated with blood. No arterial pulses were palpable in the left foot.

\section{QUESTION}

The most appropriate first step in the management of this patient in addition to resuscitation is:

A. CT arteriography.

B. CT of the abdomen.

C. Duplex ultrasound distal to the wound.

D. X-ray of the left groin and thigh.

\section{MANAGEMENT}

An X-ray of the left groin and thigh documented that all pellets were in the proximal thigh inferior to the left inguinal ligament. A blood specimen was sent for type and crossmatch (no massive transfusion protocol available at the time), a cephalosporin antibiotic was administered, and the patient was moved to the operating room.

\section{QUESTION}

The preferred operative approach would be:

A. Pass a retrograde endovascular balloon occlusion of the aorta (REBOA) device through the right groin.

B. Make a left extraperitoneal renal transplant incision for proximal control.

C. Apply an aortic compression device on top of the pressure dressing.

D. Make a longitudinal incision in the left groin proximal to the wound.

\section{MANAGEMENT}

A longitudinal incision was made in the left groin to allow for proximal control of the left common femoral artery and distal control of the left femoral vein. After encircling both femoral vessels with vessel loops, a vascular clamp was applied to the left common femoral artery and the time was noted. Bleeding from the open wound decreased significantly. A separate longitudinal incision was then made distal to the open wound. After elevation of the left sartorius muscle, the mid-left superficial femoral artery and femoral vein were mobilized and clamped. The distal femoral vein in the groin was then clamped as well.
The proximal and distal incisions in the left groin and thigh were extended into the open wound as the pressure dressing was removed. Clipping and tying of multiple vessels in the lacerated muscles of the thigh reduced bleeding considerably. There were multiple pellet wounds over a $15 \mathrm{~cm}$ length in both the left superficial femoral artery and the left femoral vein. After vigorous resuscitation with blood and products, the patient's heart rate was 95 beats per minute and the systolic blood pressure was $110 \mathrm{~mm} \mathrm{Hg}$.

\section{QUESTION}

The most appropriate management of both vascular injuries is:

A. Intravenous tubing shunts into the artery and vein.

B. Umbilical vein graft to the artery, ligate vein.

C. Polytetrafluoroethylene (PTFE) grafts to the artery and vein.

D. Saphenous vein graft to the artery, PTFE graft to the vein.

\section{MANAGEMENT}

As the patient was now reasonably stable, the injured segment of the left superficial femoral artery was resected. Fogarty balloon catheters were then passed proximally and distally. After two negative (no thrombus/embolus) passes of the balloon catheter, "regional" heparin (50 units unfractionated heparin $/ \mathrm{mL}$ saline) was administered $20 \mathrm{~mL}$ proximally and $20 \mathrm{~mL}$ distally (total 2000 units). A reversed autogenous saphenous vein graft from the right thigh was then inserted into the left superficial femoral artery with a medial extra-anatomic route to avoid the $7 \mathrm{~cm}$ blast cavity through the muscles of the thigh. After removal of the vascular clamps on the artery, palpable left pedal pulses were noted.

The injured segment of the left femoral vein was excised. Proximal and distal vascular clamps were removed sequentially to flush out any thrombus. An $8 \mathrm{~mm}$ externally supported polytetrafluoroethylene (PTFE) graft was then inserted into the left femoral vein just lateral to the saphenous vein graft in the artery (figure 1).

A "prophylactic" two-skin incision, four-compartment below-left knee fasciotomy was performed. Vigorous debridement of the lacerated and contused skin, subcutaneous tissue, and muscles in the left thigh was performed, and the cavity was packed with fine mesh gauze.

The patient did well postoperatively, and the blast cavity was clean on the eighth postoperative day (figure 2). A venogram on the 10th postoperative day demonstrated patency of the externally supported PTFE graft (figure 3). 


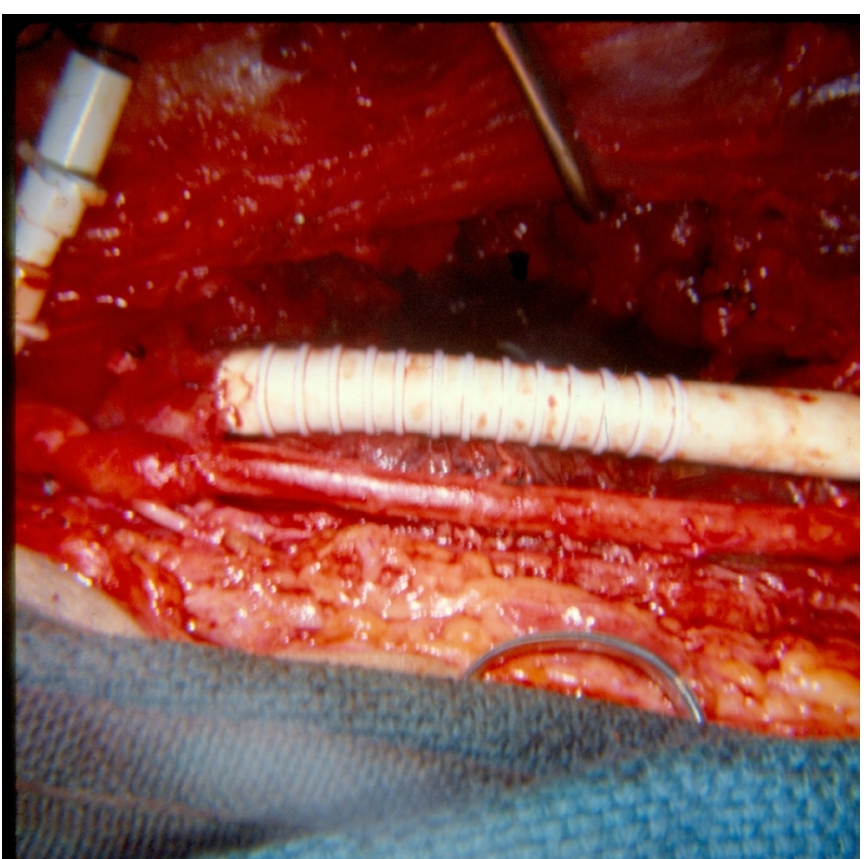

Figure 1 Autogenous saphenous vein graft in the left superficial femoral artery and externally supported $8 \mathrm{~mm}$ polytetrafluoroethylene graft in the femoral vein.

Starting on the 12th postoperative day, pus was noted to be present on the gauze dressing in the blast cavity as it was removed. This continued for another 15 days. At this point, the chief surgical resident on the trauma service met with the attending surgeon for violating his own well-known rule"wounds that don't heal contain dead tissue, infected tissue, cancer, or a foreign body." The patient had reoperations on postoperative days 27 and 35; portions of the shotgun shell were removed on both occasions from the depths of the blast cavity (figure 4), and the blast cavity healed subsequently by secondary intention. At the time of discharge on postoperative day 40, the

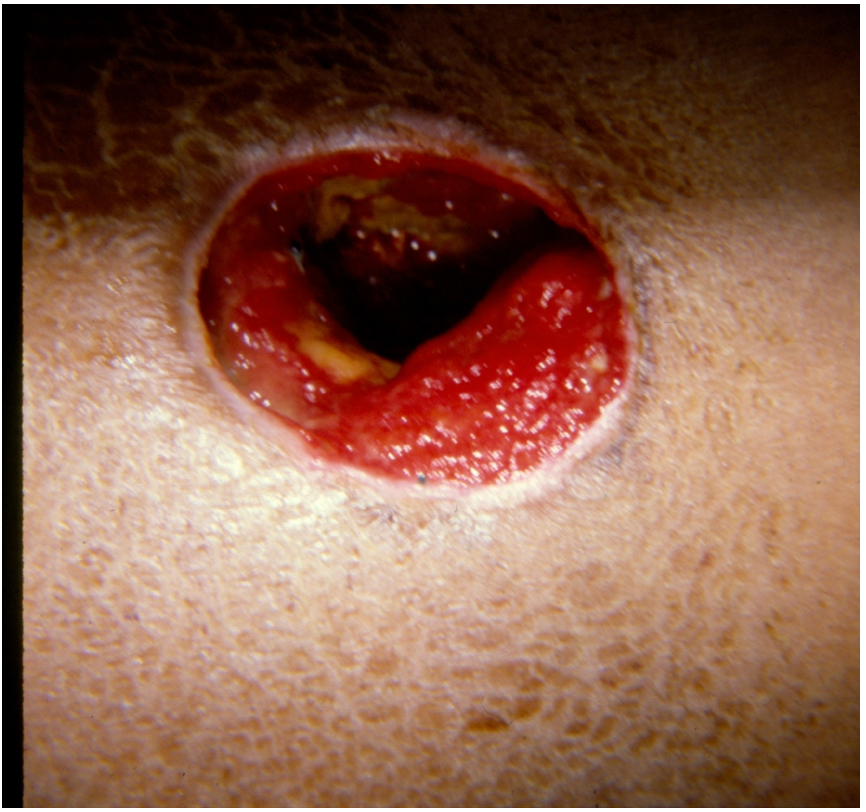

Figure 2 Shotgun blast cavity was cleaned on the eighth postoperative day.

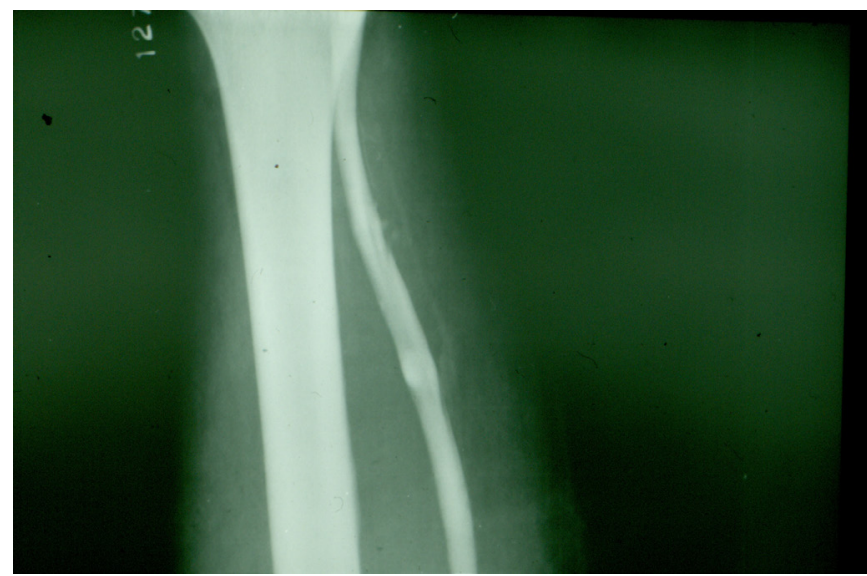

Figure 3 Venogram on the 10th postoperative day demonstrated patency of the externally supported polytetrafluoroethylene graft in the left femoral vein.

patient was advised to stop smoking and start a daily walking program, and was placed on oral aspirin $81 \mathrm{mg}$ orally every 12 hours for 3 months.

\section{DISCUSSION}

Shotgun injuries to the extremities result in a wide spectrum of injuries. This is best explained by the following statement by the late Roger T Sherman (President of the American Association for the Surgery of Trauma from 1978 to 1979): "classification of shotgun wounds entails consideration of barrel length, bore, choke, load, wadding, and range as well as high or low brass charges." ${ }^{1}$ In addition Sherman and Parrish ${ }^{1}$ in 1963 classified shotgun wounds as "penetrating" (assailant $>7$ yards from the victim), "perforating" (3-7 yards), and "massive" (<3 yards).

A patient with a close-range shotgun wound will often have many or all of the components of a "mangled extremity," that is, injuries to the soft tissue, artery, vein, bone, and nerve. ${ }^{2}$ In the patient described, there were no injuries to the bone nor nerve, and this contributed to his eventual excellent recovery.

In the modern era this patient would have had QuikClot Combat Gauze (Z-Medica, Wallingford, Connecticut) inserted into the bleeding wound and a tourniquet placed superior to it. $^{3}{ }^{4}$ Whether a tourniquet or pressure dressing is in place, proximal and distal arterial and venous control is attained

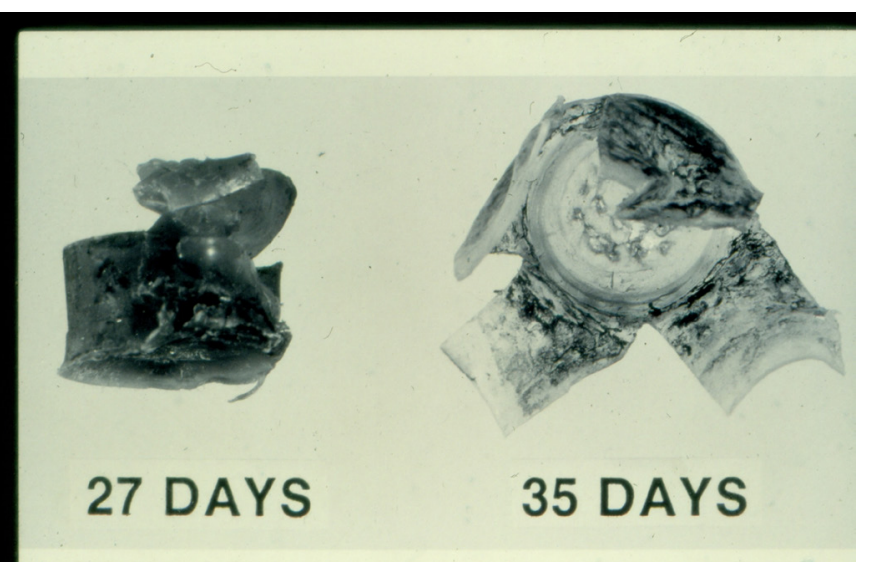

Figure 4 Pieces of shotgun shell with delayed removal from the wound on the 27 th and 35 th days. 
outside the blast cavity. Once the femoral vein is clamped superior to the area of injury, venous hemorrhage from lacerated muscle increases significantly. Controlling this delays insertion of the arterial interposition graft. So it is worthwhile to have a member of the surgical team start to retrieve the greater saphenous vein from the contralateral thigh while hemostasis is completed in the injured thigh.

Many surgeons would have inserted temporary intraluminal shunts into the injured artery and vein in such a patient. ${ }^{5}$ The vascular injuries in the patient described were $15 \mathrm{~cm}$ in length, so insertion of an Argyle (Cardinal Health, Dublin, Ohio) or the Pruitt F3 carotid artery shunt (LeMaitre Vascular, Burlington, Massachusetts) would have been impossible. An alternate choice would be large-bore blood tubing, whereas an Argyle thoracostomy tube could have been used in the femoral vein. ${ }^{56}$

The choice of an externally supported PTFE graft for interposition into the femoral vein is still controversial. The time required to create a $15 \mathrm{~cm}$ panel or spiral vein graft would have been unacceptable in this critically ill patient. The advantages of PTFE graft interposition into large peripheral veins include the following: (1) appropriate sizes off the shelf; (2) ease of insertion; (3) decreased bleeding from the area of injury and distal fasciotomy sites; (4) low infection rate when covered by viable tissue; and (5) long period of patency when externally supported grafts are used in patients placed on aspirin postoperatively (author's observation). ${ }^{78}$

The major lesson learned from the management of this patient, however, is that removal of all retained fragments of a closerange shotgun wound (wadding and others) once the patient's life and limb have been saved is mandatory. Failure to do so will result in chronic infection, purulent drainage, and failure of the blast cavity to heal.

Funding The authors have not declared a specific grant for this research from any funding agency in the public, commercial or not-for-profit sectors.

Competing interests None declared.

Patient consent Not required.

Provenance and peer review Commissioned; internally peer reviewed.

Open access This is an open access article distributed in accordance with the Creative Commons Attribution Non Commercial (CC BY-NC 4.0) license, which permits others to distribute, remix, adapt, build upon this work non-commercially, and license their derivative works on different terms, provided the original work is properly cited, appropriate credit is given, any changes made indicated, and the use is non-commercial. See: http://creativecommons.org/licenses/by-nc/4.0

\section{REFERENCES}

1. Sherman RT, Parrish RA. Management of shotgun injuries: a review of 152 cases. J Trauma 1963;3:76-86.

2. Deitch EA, Grimes WR. Experience with 112 shotgun wounds of the extremities. J Trauma 1984;24:600-3.

3. Kragh JF, Walters TJ, Baer DG, Fox CJ, Wade CE, Salinas J, Holcomb JB. Survival with emergency tourniquet use to stop bleeding in major limb trauma. Ann Surg 2009;249:1-7.

4. Dorlac WC, DeBakey ME, Holcomb JB, Fagan SP, Kwong KL, Dorlac GR, Schreiber MA, Persse DE, Moore FA, Mattox KL. Mortality from isolated civilian penetrating extremity injury. J Trauma 2005;59:217-22.

5. Feliciano DV. Vascular Trauma Revisited. J Am Coll Surg 2018;226:1-13.

6. Iserson KV, Reeter AK, Criss E. Comparison of flow rates for standard and large-bore blood tubing. West J Med 1985;143:183-5.

7. Feliciano DV, Mattox KL, Graham JM, Bitondo CG. Five-year experience with PTFE grafts in vascular wounds. J Trauma 1985:25:71-82.

8. Parry NG, Feliciano DV, Burke RM, Cava RA, Nicholas JM, Dente CJ, Rozycki GS. Management and short-term patency of lower extremity venous injuries with various repairs. Am J Surg 2003;186:631-5. 